\title{
Time to take a stand? The law on all-seated stadiums in England and Wales and the case for change
}

\author{
David Rigg ${ }^{1}$
}

Published online: 27 September 2018

(c) The Author(s) 2018

\begin{abstract}
In June 2018, the UK Government announced a review of the ban on standing at football matches in the Premier League and Championship. Nearly 30 years since the Hillsborough disaster, there is growing interest in the introduction of safestanding to football grounds in England and Wales. This paper considers official reports dating back to 1924 in an attempt to understand the woeful safety record of UK football grounds in the twentieth century, and the many missed opportunities to secure the safety of fans. The argument is made that Taylor LJ's lack of trust in both the desire and ability of footballing authorities and clubs to ensure fan safety led him to make all-seating a cornerstone of his vision for football. The current law is then reviewed before considering how safe-standing differs from the crumbling and overcrowded terraces of the 1980s. The paper concludes that stadium and crowd management measures, backed up by a robust regulatory system which has the support of all stakeholders, are necessary to ensure the continuing safety of football fans in England and Wales.
\end{abstract}

Keywords Safe standing $\cdot$ Sports Law $\cdot$ Regulation $\cdot$ Hillsborough

\section{Introduction}

The expert Report of the Technical Working Party which assisted Taylor LJ's Inquiry into the Hillsborough stadium disaster included the observation that "Whilst standing accommodation is not intrinsically unsafe, all-seater stadia bring benefits to spectator comfort, safety and crowd control". ${ }^{1}$ Taylor went on to conclude "There is no panacea which will achieve total safety and cure all problems of behaviour and crowd control. But I am satisfied that seating does more to achieve those objectives than any other single measure". ${ }^{2}$ None of the reports into crowd safety in the twentieth century had found any inherent danger in standing on the terraces, and standing areas are still permitted in the leagues beneath the Premier League and Championship provided they meet regulatory standards. The causes of the many previous incidents and disasters were the absence of basic and rudimentary safety practices concerning stadium and crowd management, primarily relating to the

David Rigg

d.rigg@mmu.ac.uk

1 Manchester Law School, Manchester Metropolitan University, Lower Ormond Street, Manchester M15 6BH, UK calculation of capacity and match day attendance. The recommendations of those earlier reports were ignored until 1973. When a system of licensing was introduced by the Safety of Sports Grounds Act 1975 (SSGA 1975), it failed to change entrenched practices and attitudes to safety. Rather than safety per se, it was Taylor LJ's determination to change attitudes and usher in a "new ethos for football" that led him to recommend all-seated stadiums.

There is now heightened interest in the introduction of "safe-standing" to football stadiums in England and Wales through the use of the rail-seat. Each ticket holder is designated a specific seat. The seat can be locked into an upright position for games where standing is allowed and each row of seats has a barrier for fans to lean on which ensures that fans occupy a specific and easily identifiable place. Safestanding areas already exist in the German Bundesliga, the Dutch Eredivisie, and, in 2016, Scottish Premier League club Celtic installed a 2600 capacity area. This paper begins by considering what was unsafe about the old standing terraces, the failure of the licensing system and what motivated Taylor LJ to recommend all-seated grounds. Attention then turns to the nature of safe-standing, whether the rail-seat

\footnotetext{
1 Taylor (1990), appendix 3, p. 95 at para 3.

2 Ibid, para 61.
} 
addresses Taylor's concerns and whether the rail-seat might already comply with existing legislation. The argument is made that, just as all-seated stadiums were never suggested as a panacea to achieve total safety and cure all problems of crowd control, neither can the same be said of safe-standing.

\section{Sixty-six years of missed opportunities}

Of the 41 disasters and incidents involving death or injury at British football grounds between 1888 and 1989, crowd pressure, either direct or leading to structural collapses, was the immediate cause of all except the 1985 Bradford and Birmingham tragedies. ${ }^{3}$ Despite this, prior to Taylor's Final Report, no report had given any serious consideration to the introduction of all-seating. The Interim Popplewell Report, which preceded the Hillsborough Inquiry by 4 years, dismissed the idea: "it failed to take account of the idiosyncrasies of football fans. A lot of them it seems do not wish to sit down; they wish to stand. They wish to stand, apparently, because there is for them a special atmosphere associated with being on the terraces. If seating is provided for them they may well tip back the seats and stand in front of them; then stand on the seats; and finally rip up the seats and use them as weapons". ${ }^{4}$ This analysis is demonstrative of the approach, common at the time, which conflated crowd control with ground safety, and assumed that hooliganism was a greater threat to spectator safety than crumbling and mismanaged grounds.

Both the Shortt Report 1924 and the Moelwyn Hughes Report 1946 contained recommendations which, if implemented and robustly administered, would have prevented Hillsborough. ${ }^{5}$ The Shortt Report recommended that the number of entrances and exits to grounds should be adequate with not less than one turnstile for every 1250 fans (the affected terrace at Hillsborough had seven turnstiles for 10,100 ticketed fans); with other turnstiles held in reserve and distributed around the circumference of the ground (there were no reserve turnstiles at Hillsborough) and clear signage stating the area of the ground to which each entrance gives access (the signage at Hillsborough was criticised for drawing fans to the overcrowded pens behind the goalmouth).

The Moelwyn Hughes Report recommended scientific calculation of the maximum number to be allowed entry to the ground and individual enclosures, counting those entering the ground by mechanical means, and central coordination of the system to ensure the admission of a safe number of spectators. At the time of the disaster, the capacity of Hillsborough was inaccurate following renovations in 1981 . There was no

\footnotetext{
3 Elliott et al. (1999), p 19.

${ }^{4}$ Popplewell (1985), para 6.16.

5 See further James (2017) pp 200-202.
}

calculation of the capacity of individual enclosures on the Leppings End and no separate access to those enclosures. Overcrowding could occur even if the overall attendance for the stand was theoretically safe. The recommendations of the Shortt and Moelwyn-Hughes Reports were not adopted and a system of self-regulation was preferred by government. The reports did not recommend seating as a solution to crowd safety, but instead emphasised the importance of basic safety features which begin with the safe management of the crowd outside of the ground. It is implicit in both reports that a mixture of ground management and crowd management measures are necessary to ensure crowd safety.

\subsection{The failure of the licensing system}

A system of licensing for "designated grounds" by local authorities was in place by the time of Hillsborough following the SSGA $1975 .{ }^{6}$ The Act included many recommendations of the Wheatley Report 1973, which followed the deaths of 66 people crushed on a stairway at Ibrox Park, Glasgow. The deficiencies of the licensing system had already been exposed by the 1985 Bradford City fire which killed 56 people. Although the Bradford City ground was not a "designated ground" for the purpose of the 1975 Act, an earlier visit by a member of the local authority Safety Team had highlighted a number of serious health and safety considerations which would need addressing if the ground ever did require a licence under the Act. The Popplewell Final Report found that both the SSGA 1975 licensing system and the associated Green Guide $^{7}$ had been "disregarded" by non-designated clubs. ${ }^{8}$

\footnotetext{
${ }^{6}$ Until 1985, to meet the vociferous concerns regarding the potential cost to smaller clubs, only those grounds accommodating more than 10,000 spectators in Divisions One and Two of the Football League, the Premier League in Scotland and certain international football and Rugby League stadia were given designated status. The Interim Popplewell Report resulted in designated status being extended immediately to all clubs in the top four English divisions and the Scottish Premier League and all major rugby league grounds. Following the Final Popplewell Report, the Safety of Sports Grounds (Designation) Order 1986/1296 added all major rugby union, cricket and athletics grounds to the licensing regime of the 1975 Act. The designation has since been reduced to 5000 spectators for football but remains 10,000 spectators for other sports: The Safety of Sports Grounds (Accommodation of Spectators) Order 1996/499.

7 The Guide to Safety at Sports Grounds, known as The Green Guide, provides detailed technical guidance on safety matters at sports grounds. It has no statutory force, but many of its recommendations will be made statutory at individual grounds by their inclusion in safety certificates issued under the Safety of Sports Grounds Act 1975 or the Fire Safety and Safety of Places of Sport Act 1987. See Department for Media, Culture and Sport (2008) The Guide to Safety at Sports Grounds (5th edn). http://www.safetyatsportsground s.org.uk/sites/default/files/publications/green-guide.pdf. Accessed 6 June 2018.

${ }^{8}$ Popplewell (1986), para 3.5.
} 
In contrast, Popplewell found that the SSGA 1975 had increased safety at designated grounds: "[M]y enquiries into the workings of the Act have shown that in designated stadia it has proved effective in ensuring improvements in safety". 9 The Hillsborough disaster showed Popplewell's confidence in the system to be misplaced. Hillsborough was a designated ground, but the stadium safety certificate had been invalid since 1981 after Sheffield City Council had failed to reduce the capacity in the stadium safety certificate to reflect alterations to the Leppings End Terrace. ${ }^{10}$ Indeed, a recommendation of Popplewell's Final Report had been for the annual renewal of safety certificates and a duty on the local authority to annually inspect the premises prior to re-issuing the certificate. ${ }^{11}$ Taylor held that the existing legislative framework "had not been strong enough to ensure the basic level of safety" and discovered multiple departures from the Green Guide (including provisions on crowd density, good practice on counting fans in, the number of turnstiles for individual sections and rate of admission per turnstile, insufficient emergency exits, and the strength and spacing of crush barriers). ${ }^{12}$ It is of note that as well as being departures from the guidance provided by the Green Guide, these shortcomings were each the subject of recommendations in the Shortt and Moelwyn Hughes Reports. Taylor LJ described the City Council and the Stadium Advisory Group, tasked with operating the licensing system at Hillsborough, variously as "inefficient", "dilatory", "casual" and "unbusinesslike". ${ }^{13}$ A defect in the licensing system had directly contributed to the Hillsborough disaster: whilst safety certificates had to specify the maximum capacity of the stadium, they did not have to specify the maximum number of spectators to be admitted to different parts of a stadium. ${ }^{14}$ The SSGA 1975 licensing system represented improvement on what little preceded it, but Hillsborough exposed its largely ineffective operation.

\subsection{A question of trust}

Although Popplewell rejected the introduction of all-seated grounds, he did encourage clubs to improve their facilities: "I have little doubt that the provision of good facilities at football grounds is likely to result in better behaviour from the fans". ${ }^{15}$ Only one English Football League stadium was

\footnotetext{
9 Ibid, para 3.4.

10 At the time of Taylor's Inquiry, Sheffield United Football Club's Bramhall Lane ground had never had a safety certificate issued despite being a designated ground since July 1984.

11 Popplewell (1986), p 64.

12 Taylor (1990), p. 24, para 140.

13 Taylor (1989) p. 51.

14 Safety of Sports Grounds Act 1975, Section 2(1)(b).

15 Popplewell (1986), p 47.
}

built between 1936 and $1988 .{ }^{16}$ Stories of dilapidated stadiums from this time are notorious, and it is a common theme of previous reports. As early as 1946, the Moelwyn Hughes Report had observed that Burnden Park was "typical of most home grounds of the leading football teams in the country. They have grown stage by stage from humble beginnings on sites acquired when the large gates of these days were not anticipated". 17 This theme continued in the Wheatley Report 1973: "The development of grounds has been somewhat haphazard in most cases, much depending on available financial resources ... [A]s a result there are few standard features in the detailed composition of football grounds and at times even in various sections of the same ground". ${ }^{18}$ The Interim Popplewell Report 1985 noted "A lot of grounds are old. The turnstiles were perfectly adequate to admit fans into the ground at a time when it mattered not on which terrace they stood. Now that there is segregation the siting of many turnstiles I have seen leaves much to be desired". 19

For Taylor, the state of football grounds was indicative of, at best, complacency and, at worst, institutionalised disregard for the safety of supporters. Whilst Popplewell had considered and dismissed all-seating as a mechanism for controlling fans, Taylor presented it as the cornerstone of his vision for "A Better Future for Football". At the heart of his recommendations was the conviction that upgraded stadiums would themselves contribute to better safety. This point is particularly pertinent to his rationale for all-seated stadiums:

"What is required is the vision and imagination to achieve a new ethos for football. Grounds should be upgraded. Attitudes should be more welcoming. The aim should be to provide more modern and comfortable accommodation, better and more varied facilities, more consultation with the supporters and more positive leadership. If such a policy is implemented it will not only improve safety. There will also be an improvement in behaviour, making crowd control easier". ${ }^{20}$

Taylor's vision would provide a justification for any improvement in facilities and accommodation, however modest, which raises the question why his proposals went so much further. Much of the discussion regarding seating in Taylor's Final Report is predicated on the matter being one which would force a change in attitudes amongst clubs and authorities who could not otherwise be trusted to arrest

\footnotetext{
${ }_{16}$ Prior to 1988, the last newly built Football League ground in England was Roots Hall, Southend, opened in 1955. Glanford Park, Scunthorpe, opened in 1988.

17 Moelwyn Hughes (1946), p 10.

18 Wheatley (1972), p 21.

19 Popplewell (1985), p 48.

20 Taylor (1990), p 12, para 59.
} 
the malaise in the game. The Final Report is peppered with criticism of stakeholders. Firstly, the FA and The Football League were criticised in the following terms:

"One would have hoped that the upper echelons ... would have taken a lead in securing reasonable safety and comfort for spectators and in enforcing good behaviour by precept and example. Unfortunately, these hopes have not generally been realised and indeed at times poor examples have been set". ${ }^{21}$

Then:

"As for the clubs, in some instances it is legitimate to wonder whether the directors are genuinely interested in the welfare of their grass-roots supporters". ${ }^{22}$

The apparent indifference of the footballing authorities to safety was longstanding. As long ago as 1924, the FA had refused to appear at the Shortt Committee. Johnes has criticised the "misplaced trust" in clubs and the game's authorities: "Clubs and the sport's authorities were run by a mixture of small businessmen and gentleman whose full-time professions lay elsewhere. They were far from knowledgeable about crowd management themselves". ${ }^{23}$

Taylor was assisted in the preparation of his Final Report by the Report of the Technical Working Party which included the recommendation that "Whilst standing accommodation is not intrinsically unsafe, all-seater stadia bring benefits to spectator comfort, safety and crowd control". ${ }^{24}$ The Final Report made no reference to this significant concession and only contains a brief passage on the safety features of all-seating:

"It is obvious that sitting for the duration of the match is more comfortable than standing. It is also safer. When a spectator is seated he has his own small piece of territory in which he can feel reasonably secure. He will not be in close physical contact with those around him. He will not be jostled or moved about by swaying or surging. Small or infirm or elderly men and women as well as young children are not buffeted, smothered or unsighted by larger and more robust people as on the terraces. The seated spectator is not subject to pressure of numbers behind or around him during the match. He will not be painfully bent double over a crush barrier. Those monitoring numbers will know exactly how many are there without having to count them in or assess the density by visual impression". ${ }^{25}$

\footnotetext{
${ }_{21}$ Ibid p 9, para 51.

22 Ibid p 10, para 53.

23 Johnes (2005), p 12.

24 Taylor (1990), p 95, para 3.

${ }^{25}$ Ibid, p 12 para 62.
}

The last point rests on the assumption that a safe number of fans are admitted to a seating area. The tragic events in all-seated South African football stadiums demonstrate that other features of stadium and crowd management measures must also be present. ${ }^{26}$ All-seating increases the likelihood that fans have their own space and are considerably less likely to be subject to pressure of numbers, but there is equally no reason why a carefully managed safe-standing area which complied with mandatory Green Guide standards could not provide the same level of safety. The Government made such a concession in 1992 by limiting the all-seated policy to the top two divisions with the implication that terracing was safe, or could be made safe, in the other divisions. Taylor simply did not countenance the possibility of managing and upgrading terraces to ensure crowd safety, and expert evidence was not called to test the possibility or project the potential costs. ${ }^{27}$

The brevity with which Taylor dealt with the safety aspects of all-seating, coupled with his condemnation of the failure of clubs and authorities to take responsibility for safety, supports the argument that he did not trust clubs and the authorities to improve grounds without such revolutionary change being imposed. In doing so, Taylor swapped the much-criticised National Membership Scheme for a policy which placed the greater responsibility on clubs to force a change in their attitude to the safety of fans. ${ }^{28}$ Minutes from the meeting of the UK Government Cabinet at which the Final Report was discussed describe it as "flawed in a number of respects". ${ }^{29}$ The Cabinet minutes make no link between the woeful safety situation at Hillsborough and the resulting disaster, instead focusing on hooliganism and crowd control: "[Taylor's] thesis that poor behaviour was the result of poor facilities at grounds was not consistent with the fact that behaviour at matches had been perfectly satisfactory when facilities at grounds had been much less developed then they were now". ${ }^{30}$ The then Home Secretary, Douglas Hurd, in a speech to the House of Commons two days after the disaster had announced that "The Government believe that the future of football in this country lies in a national membership scheme in designated grounds and now, it seems, also in providing all-seated accommodation at

\footnotetext{
${ }^{26}$ See below at Sect. 4.

27 See further Elliott et al (1999), p 22.

28 The National Membership Scheme was a proposal of the Interim Popplewell Report. Supporters would be required to present a membership card when purchasing tickets and gaining entrance to designated grounds. The Scheme was included in the Football Spectators Act 1989 but has never been brought into operation after Taylor identified a number of concerns with the Scheme in his Final Report.

29 The National Archives, Conclusions of Cabinet Minutes 25 January 1990, CAB128/96/3 p.1.

${ }^{30}$ Ibid, p.2.
} 
major football clubs. This would involve the disappearance of terraces at those grounds. It might also involve amendments to strengthen the Football Spectators Bill so that its provision for the licensing of grounds matched this concept". ${ }^{31}$ The Government's position gave every indication that all-seating was primarily viewed through the "hooligan lens" as a method of crowd control. A careful reading of the Taylor Reports makes it clear that crowd control was at most incidental to his support for the policy.

\section{The law on all-seated stadia}

The all-seated recommendation was included in the Football Spectators Act 1989 (FSA 1989) which was passing through Parliament at the time of Taylor's Inquiry. Section 9 makes it an offence to admit spectators to a designated football match without a licence to admit spectators being in force. ${ }^{32}$ To enforce the arrangements, the FSA 1989 set up the Football Licensing Authority (now the Sports Ground Safety Authority (SGSA)) to operate a licensing system for grounds used for designated football matches. ${ }^{33}$ The SGSA issues an annual licence to each club which specifies the areas of the ground to which spectators may be admitted. The all-seater requirement is included as a condition in the annual licence. The specific conditions of the licence are prescribed in secondary legislation made by the Secretary of State under Section 11:

The Secretary of State may, by order, direct the licensing authority to include in any licence to admit spectators to any specified premises a condition imposing requirements as respects the seating of spectators at designated football matches at the premises; and it shall be the duty of the authority to comply with the direction.

The list of specified premises is updated when new stadiums are built. ${ }^{34}$ Taylor's Final Report had recommended that grounds in the first and second divisions of the

\footnotetext{
${ }^{31}$ Quoted in Taylor (1990), p 15, para 84.

32 Designated football matches are those designated under s.1(2) Football Spectators (Designation of Football Matches in England and Wales) Order 2000 (SI 2000/3331) as "any association football match which is played at Wembley Stadium, at the Millennium Stadium in Cardiff or at a sports ground in England and Wales which is registered with the Football League or the Football Association Premier League as the home ground of a club which is a member of the Football League or the Football Association Premier League at the time the match is played".

${ }^{33}$ See s.10 FSA 1989 for the licensing procedure.

34 The Football Spectators (Seating Order) 2016 (2016 No. 629) added the London Stadium at the Queen Elizabeth Olympic Park, the home of West Ham United.
}

Football League (now the Premier League and Championship) and national stadia should be all-seated by the start of the 1994/1995 season. All other league football stadiums (those that are now in English Football Leagues 1 and 2) were to provide all-seated accommodation by the start of the 1999-2000 season. In 1992, the Government dropped that requirement and permitted those clubs to retain terracing provided it met certain safety standards. This is one of many inherent contradictions in the all-seating policy. Standing is considered to be too dangerous at Premier League and Championship stadiums but not at lower league grounds, some of which can attract higher attendances than Championship grounds.

Clubs promoted to the Championship for the first time have up to 3 years to convert any standing areas to seats. If the club is relegated from the Championship, it is a condition of the licence that the ground must remain all-seated. If a club is relegated before the 3 years has expired, and at the time it is relegated it has not yet converted its ground to allseating, when it is next promoted any time previously spent in the Championship or Premiership is counted towards the 3 years. The all-seated policy also applies to the new home ground of any club whose existing ground is all-seated, but a new order would be required as seating orders are ground specific. ${ }^{35}$

The FSA 1989 does not extend to Scotland where there are no legislative provisions requiring all-seated accommodation. The SSGA 1975 licensing system applies and requires the owners of sports grounds in Scotland to apply to the local authority for a safety certificate. The local authorities are advised by Safety Advisory Groups on the basis of the Green Guide. The Scottish Premier League (SPL) makes it a condition of membership that clubs provide allseated accommodation. This condition was relaxed in 2011 to allow clubs to apply to the SPL Board to pilot safe-standing areas. ${ }^{36}$ Where approval by the SPL is given, further approval is then required from the local authority. In July 2016, SPL club Celtic installed 2600 rail-seats at Celtic Park. This is the first safe-standing area to be used by fans at a UK football match.

Taylor's recommendation that all designated sports grounds be all-seated (under the SSGA 1975 this would have applied to any sports ground that held more than 10,000 spectators) has never been taken up by government. Other sports grounds are not covered by the all-seating requirement and licences issued by the SGSA do not apply to

\footnotetext{
35 Explanatory Memorandum to The Football Spectators (Seating Order) 2016 (2016 No.629) at para. 7.3.

${ }^{36}$ See Scottish Professional Football League (2011) SPL Statement: Rule Changes. https://spfl.co.uk/news/article/spl-statement-rulechanges-2011-12-19/. Accessed 6 June 2018.
} 
non-football events, such as concerts or rugby matches, taking place at a football ground. This anomaly means that a dual use stadium, such as Ashton Gate which is the home ground of Bristol City Football Club and Bristol Rugby, has rail-seating installed which allows fans to stand at a rugby match but cannot be used at a football match. ${ }^{37}$

\section{What is safe-standing and does it address the concerns expressed by Taylor $L J$ and earlier reports?}

The Football Supporters' Federation (FSF) has been at the forefront of a campaign to bring safe-standing areas to UK football grounds. The FSF was formed in the wake of the Heysel disaster, 1985, and describes itself as "the democratic organisation representing the rights of fans and arguing the views of football supporters in England and Wales". ${ }^{38}$ In March 2011, it launched a safe-standing campaign "to persuade the Government, football authorities and football clubs to accept the case for introducing, on a trial basis, limited sections of standing areas at selected grounds in the stadiums of Premier League and Championship football clubs" ${ }^{39}$ The campaign, which builds on research of existing safe-standing areas at grounds in Europe, has the support of 26 clubs and the SPL.

Although some European clubs provide ad hoc seating on terraces through the use of a fold away seat where the seat is folded away under terrace steps when standing is permitted, or the more rudimentary "bolt on" seat, safestanding as envisaged by the FSF is radically different. The "safe-standing" used at Celtic Park and widely used in the Bundesliga and by Dutch Eredivisie clubs PSV Eindhoven and Ajax involves a so-called "rail-seat": typically a $370 \mathrm{~mm} \times 500 \mathrm{~mm}$ seat with a $900 \mathrm{~mm}$ high rail for fans to lean on when standing which ensures fans have a specific space in which to stand and would discourage migratory crowd movement during a game. The seat folds back and can be locked into an upright position for games where standing is allowed and unlocked to allow use of the seat at games in, for example, UEFA and FIFA competitions which require all-seated stadiums. The very term "terrace" is a misnomer

\footnotetext{
37 See further Keppel-Palmer (2014) Stand up for seating: Why allseated football stadia should be reconsidered. Law in Sport. https:// www.lawinsport.com/topics/articles/item/stand-up-for-seating-whyall-seated-football-stadia-should-be-reconsidered. Accessed 6 June 2018.

${ }^{38}$ Football Supporters' Federation (2018). http://www.fsf.org.uk/about-us/. Accessed 6 June 2018

39 Ibid.

http://www.fsf.org.uk/campaigns/safe-standing. Accessed 6 June 2018.
}

when describing rail-seating technology for two significant reasons: the barrier, which accompanies each row of railseats, is continuous to prevent crowd surging (including at the corner of grounds), and each fan is allocated a specific rail-seat. There are other examples of safe-standing areas outside of Europe, including Major League Soccer side Orlando City.

The causes of previous incidents and disasters were the absence of basic and rudimentary safety practices concerning stadium management and crowd control measures, primarily relating to the calculation of capacity and match day attendance. Rail-seating appears to address the specific recommendations of the line of reports dating back to 1924 . The characteristics of a rail-seat satisfy Taylor LJ's fourpoint justification for all-seating:

the fan has his own small piece of territory in which he can feel reasonably secure; he is not subject to pressure of numbers behind or around him during the match; he will not be painfully bent double over a crush barrier; those monitoring numbers will know exactly how many are there without having to count them in or assess the density by visual impression. ${ }^{40}$

However, all-seated areas are only safe provided a safe number of fans are allowed entry and the other features of good stadium crowd management are present. The insufficient number of turnstiles at Hillsborough which led to the opening of Gate $\mathrm{C}$ to relieve crushing outside of the ground, together with the lamentable match day command and the presence of perimeter fencing, does not support an argument that all-seating would have prevented all the fatalities that day. A safe-standing area is no different and requires a high level of stadium and crowd management, such as effective policing and stewarding procedures, strict control of capacities and measurement of attendance, and high-resolution CCTV, all of which are common practice today at designated stadiums in England and Wales.

The findings of the Hillsborough Inquest in April 2016 have added greater cogency to the arguments in favour of safe-standing by confirming the causes of the disaster and removing any doubt that the practice of standing on the terraces per se contributed to the disaster. ${ }^{41}$ The Inquest jury found that the immediate cause of the disaster was crushing caused by the admission of a large number of supporters through the exit gates. A number of specific findings of fault were made against South Yorkshire Police in respect of errors and omissions in policing the crowd both inside and

\footnotetext{
40 Taylor (1990), p 12, para 62.

41 See HC Deb 27 April 2016, vol 608, cols 1433-1437 for the Statement of the Home Secretary to the House of Commons which contains the findings of the Inquest Jury.
} 
outside the stadium; Sheffield Wednesday Football Club in respect of failing to address known defects in the stadium and failing to improve access to the Leppings End and its turnstiles; and Sheffield City Council for failing to investigate the earlier changes made to the Leppings End which should have reduced its capacity and led to an update to the stadium safety certificate. More than 25 years since the Taylor Reports, the findings of the Inquest have changed the political context of the safe-standing debate by confirming the overriding importance of robust stadium and crowd management measures rather than resting on the assumption that all-seating provides the only answer.

The dangers inherent in a poorly managed all-seated stadium are exemplified by the disaster at Ellis Park, Johannesburg, 11 April 2001, where 43 died following overcrowding. In circumstances familiar to observers of English football in the 1970s and 1980s, around 80,000 fans attended a 60,000 capacity stadium. The subsequent report found that, inter alia, a mixture of poor crowd management outside of the stadium with thousands attempting to purchase tickets immediately before the match, an insufficient number of turnstiles, no one person in overall command to make decisions as the disaster unfolded, and a system of unreserved seating were to blame. Recommendations followed those of the Shortt and Moelwyn Hughes Reports and included the counting of fans as they enter the ground with the information continuously fed to a central point, a number of turnstiles that is commensurate with the ground capacity, and the creation of a trained body of stewards. ${ }^{42}$ In July 2017, delays outside at the all-seater FNB Stadium, Johannesburg, which had hosted games at the 2010 World Cup, led to a stampede which left two fans dead.

\subsection{Unsafe seating}

There is a growing argument that the introduction of safestanding might itself be justified on safety concerns regarding persistent standing in seated areas. Safety in seated areas was a motivating factor for Ajax to introduce rail-seating after a fan was seriously injured after falling off the first tier of a stand and other examples of progressive crowd collapse where standing fans fall forward in a domino effect. The principle safety risk exists when spectators fall over the seat in front of them, which has not been designed for standing spectators. Standing in seated areas is also more likely to result in standing spectators spilling out into gangways and blocking exits and encourage children to stand on seats to

42 See further Commission Of Inquiry Into The Ellis Park Stadium Soccer Disaster Of 11 April 2001 (2002).

https://www.gkstill.com/Support/Links/Documents/2002-ngoep e.pdf. Accessed 6 June 2018. see over the heads of those in front. ${ }^{43}$ The English law on all-seated stadiums only stipulates that seats be provided and it is not a criminal offence if a fan decides not to use the seat. In reality, ground regulations usually make it a breach of the entry ticket's terms and conditions for spectators to stand during a match.

In November 2013, a Joint Statement "Standing in Seated Areas at Football Grounds" was released by a number of key regulatory bodies including the Sports Grounds Safety Authority, FA Premier League and Football League. ${ }^{44}$ The report noted that, "it is preferable for standing in seated areas to be addressed primarily through the education, persuasion and positive management of spectators. However, such measures alone have not always achieved the desired results. To the extent that they continue to prove insufficient, they may need to be backed up by more robust action". ${ }^{45}$ The Report reminds clubs that standing in seated areas can present a serious safety hazard and regulatory sanctions exist including the SGSA's power to impose conditions in the local authority's safety certificate for the ground, such as reducing capacity at matches where safety concerns are anticipated. ${ }^{46}$ The desire to prevent persistent standing in seated areas was a key factor behind West Bromwich Albion Football Club's application to the SGSA for permission to pilot 3600 rail-seats for the 2018/19 season which was rejected by the Department for Digital, Culture, Media and Sport. ${ }^{47}$

\subsection{How safe-standing could be introduced}

The success of the Celtic Park safe-standing pilot has emboldened advocates of safe-standing in England and Wales. The introduction of safe-standing areas could be achieved relatively straightforwardly by the introduction of secondary legislation which removed the requirement for all-seating in the licence issued by the SGSA. This would require revision of guidance in the Green Guide to incorporate recommendations on safe-standing. There is also an argument that rail-seating already complies with the current law on all-seated stadia. In February 2017, the SGSA published a document outlining a process for clubs in England and Wales who do not come within the all-seated

\footnotetext{
${ }^{43}$ Sports Grounds Safety Authority et al (2013), pp 10-11.

${ }^{44}$ Ibid.

45 Ibid, $\mathrm{p} 3$.

46 Ibid, pp 6-7.

${ }^{47}$ See BBC (2018) Safe standing: West Bromwich Albion have proposal rejected by government. https://www.bbc.co.uk/sport/footb all/43701400. Accessed 6 June 2018.
} 
requirement to install rail-seating. ${ }^{48}$ The SGSA makes it clear that a successful application would carry considerable risk for the club if it was subsequently promoted to the Championship: "unless Government policy changes, any club which had installed dual purpose seating/standing areas would be unlikely to be able to secure a licence for this area once they have been in the Championship or Premier League for more than 3 years". ${ }^{49}$ This is highly debatable. The Green Guide specifies minimum dimensions for new seats as $460 \mathrm{~mm}$ wide and $700 \mathrm{~mm}$ deep, but there is no definition of "seated accommodation" in the FSA 1989. ${ }^{50}$ Rail-seats which are locked into a seated position satisfy the requirement for all-seated accommodation in UEFA and FIFA competitions. Provided correctly dimensioned railseats are locked into a seated position in England and Wales, it would be difficult to argue that a club was not providing "seated accommodation" under the FSA 1989 if the matter went to judicial review. Any challenge against a contrary finding would benefit from the rules of statutory interpretation. Literally, in the absence of further definition, "seated accommodation" is somewhere to sit and the dimensions of a rail-seat comply with the Green Guide recommendations on seated accommodation. The mischief which the all-seated policy was designed to remedy was crushing, and the rail for each row guards against this. By extension, the purpose of the all-seating policy was to make stadiums safer, which rail-seating achieves. Indeed, the presence of a rail for each row reduces the likelihood of injuries suffered when standing in a seated area.

The arguments above, though, understate the political reality of the situation and the symbolic nature of a policy drafted in the aftermath of what remains the worst sporting disaster in the UK and which has dominated public consciousness for nearly 30 years. Primary legislation would not be necessary but it would be politically expedient. The Liberal Democrats included safe standing as a manifesto pledge in 2015 and a Private Member's Bill failed in 2010 for lack of parliamentary time. The Safe Standing (Football Stadia) Bill proposed an amendment to Section 11 of the FSA 1989 which would require a licence to stipulate the number of spectators for whom seating is provided and the number of spectators for whom standing accommodation is provided but no condition that seating be required for all

\footnotetext{
${ }_{48}$ Sports Grounds Safety Authority (2017) Process for consideration of the installation of dual-purpose seating and standing areas by clubs not subject to the all-seater requirement. http://www.safetyatsp ortsgrounds.org.uk/sites/default/files/documents/SGSA $\% 20 \mathrm{dual} \% 20$ purpose $\% 20$ area $\% 20$ licensing $\% 20$ process $\% 20$ FINAL.pdf. Accessed 6 June 2018.

49 Ibid $\mathrm{p} 2$.

50 The Guide to Safety at Sports Grounds (2008) p 116.
}

spectators. ${ }^{51}$ Although political momentum for a change in the law is growing, the Department for Culture, Media and Sport has consistently reiterated it is "unconvinced" on the matter and in April 2018 rejected an application by Premier League club West Bromwich Albion to install a pilot area. In June 2018, a debate was held in the House of Commons following an online petition calling for the introduction of safe-standing at Premier League and Championship grounds which was signed by more 112,000 people. ${ }^{52}$ The speeches made by Members of Parliament (MPs) were mindful of public opinion on the matter which suggests strong support for a change in the law. MPs were overwhelmingly in favour of allowing clubs the choice to install safe-standing areas. The Minister responsible concluded by announcing a review of the existing policy but warned "Change cannot and should not happen overnight on something as serious as football ground safety". 53

\section{Conclusion}

The all-seated requirement has ushered in wholescale changes to the ethos of football in the UK. Since the Final Taylor Report, there have been numerous new stadiums built and a number of large modernisation projects of existing stadiums. The changes brought by all-seating have been subject to widespread criticism regarding the commercialisation of the game, price inflation and demographic change that are beyond the scope of this paper. What is not in doubt is that football grounds are safer today than at any point in the history of the game. The wholescale changes in the attitudes of the footballing authorities towards spectator safety mean that new safe standing technology is highly unlikely to herald a return to the bad days of the unmanaged, or unmanageable, terrace. Safe-standing, as the name suggests, does not mean a return to the days of the crumbling and overcrowded terraces. However, just as all-seated stadiums were never suggested as a panacea to achieve total safety and cure all problems of crowd control, neither can the same be assumed of safe-standing. A hundred years of missed opportunities, together with sobering examples from modern all-seated stadia in South Africa, demonstrate that stadium and crowd management measures, backed up by a robust regulatory system and the support of clubs and the authorities, are necessary to ensure the continuing safety of football fans in England and Wales. Thirty years since the worst sporting

\footnotetext{
51 Safe Standing (Football Stadia) Bill 2010, Bill 121.

52 See https://petition.parliament.uk/petitions/207040. Accessed 6 June 2018.

${ }^{53}$ HC Deb 25 June 2018, vol 243, col 274WH.
} 
disaster in the UK, it is unsurprising that no consensus has yet emerged on this emotive subject.

Acknowledgements I wish to thank Professor Mark James for his guidance and sharing his expertise in this field.

Open Access This article is distributed under the terms of the Creative Commons Attribution 4.0 International License (http://creativeco mmons.org/licenses/by/4.0/), which permits unrestricted use, distribution, and reproduction in any medium, provided you give appropriate credit to the original author(s) and the source, provide a link to the Creative Commons license, and indicate if changes were made.

\section{References}

BBC (2018) Safe standing: West Bromwich Albion have proposal rejected by government. https://www.bbc.co.uk/sport/footb all/43701400. Accessed 6 June 2018

Department for Media, Culture and Sport (2008) The guide to safety at sports grounds, 5th edn. http://www.safetyatsportsgrounds.org.uk/ sites/default/files/publications/green-guide.pdf. Accessed 6 June 2018

Elliott D, Frosdick S, Smith D (1999) The failure of 'legislation by crisis'. In: Frosdick S, Walley L (eds) Sport and safety management. Butterworth-Heinemann, Oxford

James M (2017) Sports law, 3rd edn. Palgrave Macmillan, Basingstoke

Johnes M (2005) Heads in the sand: football, politics and crowd disasters in twentieth-century Britain. In: Darby P et al (eds) Soccer and disaster international perspectives, 1st edn. Routledge, London, pp 10-28

Keppel-Palmer M (2014) Stand up for seating: Why all-seated football stadia should be reconsidered. Law in sport. https://www.lawin sport.com/topics/articles/item/stand-up-for-seating-why-all-seate d-football-stadia-should-be-reconsidered. Accessed 6 June 2018

Moelwyn Hughes (1946) Enquiry into the disaster at Bolton Wanderers' football ground on the 9th March, 1946. HMSO, Cmnd 6846

Popplewell J (1985) Committee of inquiry into crowd safety at sports grounds (interim report), HMSO, Cmnd 9585

Popplewell J (1986) Committee of inquiry into crowd safety at sports grounds (final report). HMSO, Cmnd 9710

Scottish Professional Football League (2011) SPL statement: rule changes. https://spfl.co.uk/news/article/spl-statement-rule-chang es-2011-12-19/. Accessed 6 June 2018

Shortt E (1924) Report of the departmental committee on crowds. HMSO, Cmd 2088

Sports Grounds Safety Authority et al (2013) Standing in seated areas at football grounds. http://www.safetyatsportsgrounds.org.uk/ sites/default/files/publications/standing-in-seated-areas-2013. pdf. Accessed 6 June 2018

Sports Grounds Safety Authority (2017) Process for consideration of the installation of dual purpose seating and standing areas by clubs not subject to the all-seater requirement. http://www.safetyatsp ortsgrounds.org.uk/sites/default/files/documents/SGSA\%20dua $1 \% 20$ purpose $\% 20$ area $\% 20$ licensing $\% 20$ process $\% 20$ FINAL.pdf. Accessed 6 June 2018

Taylor LJ (1989) The Hillsborough stadium disaster (interim report). HMSO, Cmnd 765

Taylor LJ (1990) The Hillsborough stadium disaster (final report). HMSO, Cmnd 962

The National Archives, Conclusions of Cabinet Minutes 25 January 1990, CAB128/96/3

Wheatley (1972) Report on crowd safety at sports grounds. HMSO, Cmnd 4962 